\title{
Development and evaluation of screening strategies for Chlamydia trachomatis infections in an STD clinic
}

\author{
Y T H P van Duynhoven, M J W van de Laar, J S A Fennema, G J J van Doornum, \\ J A R van den Hoek
}

\begin{abstract}
Objectives-To identify predictors for Chlamydia trachomatis infection among visitors of an STD clinic in Amsterdam in 1986-1988. To design predictor-based screening programmes for $C$ trachomatis. To evaluate the chosen screening strategy in 1993.
\end{abstract}

Methods-In 1986-1988, 947 heterosexual men and 648 women participated in the study. A medical history was recorded, a physical examination took place and samples were taken for laboratory diagnostics. Information for 1993 was available from routine databases.

Results-C trachomatis infections in heterosexual men in 1986-1988 (prevalence $15 \cdot 8 \%$ ) were independently associated with: age under 26 years, being an STD contact, coitarche below 13, last sexual contact with a non-prostitute, (muco)purulent urethral discharge and ten or more leukocytes per microscopic field of urethral smear or urine. For women (prevalence $21.5 \%$ ) independent predictors were age under 26 , no history of STD, being an STD contact, cervical friability, (muco)purulent cervical discharge, presence of clue cells and ten or more leukocytes per field of urethral smear. Screening men with one anamnestic predictor for $\boldsymbol{C}$ trachomatis and ten or more leukocytes in smear or urine (59\% of men) would detect $93 \%$ of the cases in 1986-1988. For females only universal screening proved to be suitable. After the introduction of a screening strategy in 1989 (universal for women, indicated by urethritis for men), a strong decline was found in the $\boldsymbol{C}$ trachomatis prevalence for all subgroups in 1993, excluding prostitute's clients and Turkish men.

Conclusions-In 1993 the overall C trachomatis prevalence had declined among the attendants of the STD clinic. It seems likely that this fall was caused both by the screening programme and the reduction of risk behaviour.

(Genitourin Med 1995;71:375-381)

Keywords: Chlamydia trachomatis; screening strategy

Introduction

Nowadays it is widely recognised that Chlamydia trachomatis is the most common sexually transmitted bacterial pathogen in industrialised countries. Clinical features of urogenital chlamydial infections include urethritis, proctitis, mucopurulent cervicitis, epididymitis and pelvic inflammatory disease. However, $C$ trachomatis infections are often asymptomatic or cause only mild (nonspecific) signs or symptoms. In women infections may result in severe sequelae, such as infertility or ectopic pregnancy. Asymptomatic infections may represent an important reservoir for the agent and treating patients who have symptoms along with their partners may not be effective in reducing the prevalence of $C$ trachomatis infection. Screening may offer an additional strategy for the control of $C$ trachomatis infection, but selective screening, based on single historical or clinical risk factors, was found to have a relatively low predictive value. ${ }^{1-5}$ Combinations of these factors will increase this value. ${ }^{6-10}$

The aim of this study was to estimate the STD prevalence among visitors attending a sexually transmitted disease (STD) clinic in Amsterdam from 1986 to 1988 and to study predictors for $C$ trachomatis infection in order to identify potential high-risk subgroups. Until the start of the study the detection of $C$ trachomatis was by cell culture (the gold standard at that time) and was not routinely performed among attendants, but on medical grounds only. To achieve cost reduction in comparison with universal screening, the predictors for $C$ trachomatis infection were used to design selective screening programmes. From 1989 onwards, material for the diagnosis of $C$ trachomatis infection was routinely collected for all women attending the clinic as well as for men with urethritis and, since October 1991, for all men in general. ${ }^{11}$ The effect of this strategy was studied with respect to the prevalence and the risk factors for $C$ trachomatis infection in the clinic population in 1993.

\section{Population and methods}

Study population 1986-1988 The study was carried out at the STD clinic in Amsterdam between September 1986 and December 1988. The first eight men and first four women who visited the clinic on two days each week were enrolled in the study. The $2: 1$ ratio for sampling was based on the gender distribution among visitors in the preceding years. Individuals with a prior visit in the past four weeks were excluded. Other exclusion criteria were plans to leave the Netherlands within six 
weeks and use of antibiotics in the past four weeks. After receiving information about the study, participants had to sign an informed consent form. All participants were questioned by a physician (JSAF, JARH) about age, nationality, native country, drug use in the past three months, age at first sexual contact, sexual preference, type (casual, steady, commercial) of last and former sexual contacts, number of sexual contacts (past month, half year and lifetime), condom use for casual contacts in the past six months, history of STD and genitourinary complaints. Additionally, women were asked about their menstrual cycle, current type of contraceptives and for oral contraceptives about the period of use. A physical examination was carried out and samples of blood and specimens for culture and direct microscopy were obtained. In the analysis presented here, homosexual men were excluded.

For heterosexual men, urethral samples were taken for culture for Neisseria gonorrhoeae and for $C$ trachomatis and if discharge was available for Gram-staining. The urethral discharge was categorised as mucous, mucopurulent or purulent. The number of leukocytes was determined in the Gram-stained smear or in first catch urine if less than ten leukocytes were present in the discharge smear. Nongonococcal urethritis was diagnosed when on average ten or more leukocytes per field were found (magnification $400 \times$ ) in the absence of intracellular diplococci.

In women, first rectal samples for $N$ gonorrhoeae and $C$ trachomatis culture were taken. After the cervix was wiped, endocervical discharge was categorised as mucous, mucopurulent or purulent. The swab test was used for visualising the discharge. Then endocervical samples were taken for cultures for $N$ gonorrhoeae and $C$ trachomatis and for Gram-staining. The cervix was also evaluated for ectopy, erythema and cervical bleeding induced by taking samples (hereafter called cervical friability). Finally, urethral material was taken for cultures for $N$ gonorrhoeae and $C$ trachomatis and for Gram-staining. A sample of the oropharynx for $C$ trachomatis and $N$ gonorrhoeae culture was only indicated when the patient reported orogenital sexual contact in the preceding six months. A patient was defined $C$ trachomatis positive if at least one of the samples was found positive by cell culture.

Statistical methods Univariate analyses identified significant predictors of $C$ trachomatis infection in 1986-1988 using the $\chi^{2}$ test and the two-tailed Fisher exact test. The analyses were done separately for heterosexual men and women. Variables associated with $C$ trachomatis infection $(p \leqslant 0.05)$ were further analysed by logistic regression analysis to identify independent predictors. A variable was included in the logistic model if the likelihood ratio test was significant (alpha $=0.05$ ) or when the beta coefficient of a variable already in the model changed by at least ten percent. Odds ratios (OR) are presented with $95 \%$ confidence limits (95\% CL).

Various sets of independent predictors of $C$ trachomatis infection were used to develop screening strategies. For each strategy the proportion of the target population to be tested, the sensitivity and the positive predictive value (PPV) were calculated. The criteria for an appropriate screening programme were defined as a sensitivity of $90 \%$ for men and $95 \%$ for women (because of more severe complications). Also, the prevalence in the population to be screened had to exceed the prevalence in the target population in order to be cost-effective. The former prevalence corresponds with the PPV. A PPV was chosen, that is, arbitrarily, 1.5 times the prevalence in the target population.

At first, all independent predictors for $C$ trachomatis infection were included in the screening programme. Subsequently, the predictors were dropped one by one until eventually $90 \%$ and $95 \%$ of the infected men and women respectively were detected by the programme (theoretical approach). In addition, in a more medical approach the sensitivity and PPV of the independent predictors for $C$ trachomatis infection reported during the medical history were calculated and the surplus value of predictors originating from the physical examination and laboratory diagnostics was studied. Finally, data from visitors in 1993 were used to estimate the influence of the chosen screening strategy.

Population STD clinic 1993 Data were collected routinely for all visitors attending the STD clinic. Information on direct microscopy and results of the physical examination were not entered in the database. Available computerised data include age, nationality, history of STD, sexual preference, being an STD contact or not, existence of commercial sexual contacts and current STD diagnoses. In 1993 $C$ trachomatis infection was diagnosed by culture for women and by enzyme-linked immunosorbent assay (ELISA) or culture for men. A previous evaluation of culture and ELISA in comparison with an expanded gold standard using also polymerase chain reaction results, revealed that the sensitivity of the cell culture of cervical swabs and the ELISA was $71 \cdot 1 \%$ and $65 \cdot 8 \%$, respectively. ${ }^{12}$ The difference between the sensitivity of culture and ELISA was even less for male urethral swab specimens (personal communication GJJ van Doornum). The data were compared with those from the period 1986-1988 to determine whether the screening strategy implemented in 1989 had changed the $C$ trachomatis infection prevalence.

\section{Results}

\section{Non-participation in the study}

During the period 1986-1988 2,175 visitors were eligible for the study. The participation rate was $84 \%$. For $91 \%$ of the non-participants information on diagnoses and demographic and sexual characteristics was available from the routine data. Analyses showed that male non-participants were younger (on average two years), had a foreign nationality more often (especially Morocco 
Table 1 Sociodemographic and sexual characteristics of 947 heterosexual men and 648 women attending an STD clinic in Amsterdam, 1986-1988

\begin{tabular}{|c|c|c|c|c|}
\hline Variable & $\begin{array}{l}\text { Men } \\
n\end{array}$ & $\begin{array}{l}(n=947) \\
\%\end{array}$ & $\begin{array}{l}\text { Women } \\
n\end{array}$ & $\begin{array}{l}(n=648) \\
\%\end{array}$ \\
\hline \multicolumn{5}{|l|}{ Native country } \\
\hline The Netherlands & 526 & $55 \cdot 5$ & 467 & $72 \cdot 1$ \\
\hline Surinam/Antilles & 137 & $14 \cdot 5$ & 69 & $10 \cdot 6$ \\
\hline Morocco & 43 & $4 \cdot 5$ & 6 & 0.9 \\
\hline Turkey & 47 & $5 \cdot 0$ & 2 & $0 \cdot 3$ \\
\hline Other & 194 & $20 \cdot 5$ & 104 & $16 \cdot 0$ \\
\hline \multicolumn{5}{|l|}{ Number of partners last month } \\
\hline 1 & 533 & $56 \cdot 3$ & 410 & $63 \cdot 3$ \\
\hline $2-5$ & 319 & $33 \cdot 7$ & 120 & $18 \cdot 5$ \\
\hline$\geqslant 6$ & 8 & $0 \cdot 8$ & 65 & $10 \cdot 0$ \\
\hline none & 79 & $8 \cdot 3$ & 40 & $6 \cdot 2$ \\
\hline Orogenital contact $\leqslant 6 \mathrm{mnd}$ & 478 & $50 \cdot 5$ & 472 & $72 \cdot \overline{8}$ \\
\hline Passive anal contact $\leqslant 6$ mnd & - & - & 82 & $12 \cdot 7$ \\
\hline Work as prostitute & 0 & $0 \cdot 0$ & 96 & $14 \cdot 8$ \\
\hline History of STD* & 604 & $63 \cdot 8$ & 319 & $49 \cdot 2$ \\
\hline \multicolumn{5}{|l|}{ Diagnosis of current STD } \\
\hline gonorrhoea & 101 & $10 \cdot 7$ & 37 & $5 \cdot 7$ \\
\hline chlamydia & 150 & $15 \cdot 8$ & 139 & $21 \cdot 5$ \\
\hline (inclusive gonorrhoea + chlamydia & 18 & 1.9 & 17 & $2 \cdot 6$ \\
\hline
\end{tabular}

ॠHistory of gonorrhoea, chlamydia, syphilis, urethritis, genital herpes or condylomata acuminata and salpingitis for women. women (range 7-32). For men a foreign native country was more common than for women, $44 \%$ and $28 \%$, respectively. Approximately half of the women and two-thirds of the men reported a history of STD.

\section{CT prevalence and predictors of infection}

The prevalence of $C$ trachomatis infection, $15 \cdot 8 \%$ for heterosexual men and $21.5 \%$ for women, exceeded the prevalence of gonorrhoea, $10 \cdot 7 \%$ and $5.7 \%$, respectively. Urogenital symptoms were less present in $C$ trachomatis-infected women (52\%: symptoms of vaginal discharge, dysuria, frequent miction of small amounts or lower abdominal pain) than in infected men (69\%: symptoms of dysuria or urethral discharge).

Predictors that were significant in univariate analyses but not in logistic regression analyses are presented in table 2 . Those that were significant in both the univariate and logistic regression analyses are shown in table 3. C trachomatis infections in heterosexual men were independently associated with: age below 26 years, being an STD contact, age at first sexual contact below 13 years, last sexual contact

Table 3 Independent predictors of Chlamydia trachomatis infection in female and heterosexual male visitors of an STD clinic in Amsterdam 1986-1988, identified by logistic regression analysis

Characteristics of the study population

General characteristics for the participants are shown in table 1 . The mean age for the 947 heterosexual men was 32 years (range 14-74) and for the 648 women was 28 years (range 15-53). The mean age at first sexual contact was 17, both for men (range 6-38) and

Table 2 Predictors that were only univariately associated with Chlamydia trachomatis infection in female and heterosexual male visitors of an STD clinic in Amsterdam 1986-1988

\begin{tabular}{|c|c|c|c|}
\hline & $n$ & $\begin{array}{l}\% C T \\
\text { positive }\end{array}$ & $\begin{array}{l}\chi^{2} \text {-test, } \\
p \text {-value }\end{array}$ \\
\hline \multicolumn{4}{|l|}{$\begin{array}{l}\text { Heterosexual men: } \\
\text { Native country }\end{array}$} \\
\hline European & 576 & $17 \cdot 0$ & \multirow[t]{3}{*}{0.033} \\
\hline Turkey & 47 & $8 \cdot 5$ & \\
\hline Other Asian country & 63 & $6 \cdot 3$ & \\
\hline \multicolumn{4}{|l|}{ Condom use in casual contacts } \\
\hline Always & 105 & $4 \cdot 8$ & \multirow[t]{5}{*}{$0 \cdot 15$} \\
\hline Almost always & 70 & $12 \cdot 9$ & \\
\hline Often & 72 & $16 \cdot 7$ & \\
\hline Sometimes & 60 & $20 \cdot 0$ & \\
\hline Never & 355 & $18 \cdot 0$ & \\
\hline \multicolumn{4}{|l|}{ Urethral discharge } \\
\hline Absent & 579 & $10 \cdot 2$ & \multirow[t]{2}{*}{$<0.001$} \\
\hline Present & 362 & $25 \cdot 1$ & \\
\hline \multirow{2}{*}{\multicolumn{4}{|c|}{$\begin{array}{l}\text { Women: } \\
\text { Contraceptives }\end{array}$}} \\
\hline & & & \\
\hline None & 153 & $15 \cdot 7$ & \multirow[t]{5}{*}{$<0.001$} \\
\hline Oral contraceptives (OAC) & 310 & $29 \cdot 7$ & \\
\hline Intra Uterine Device (IUD) & 65 & $18 \cdot 5$ & \\
\hline Condom/other barrier method & 71 & 12.7 & \\
\hline Operation & 34 & 5.9 & \\
\hline \multicolumn{4}{|l|}{ Length of use OAC } \\
\hline$<0.5$ year & 49 & $24 \cdot 5$ & \multirow[t]{3}{*}{0.031} \\
\hline $0.5-3$ years & 114 & $38 \cdot 6$ & \\
\hline \multirow{2}{*}{\multicolumn{3}{|c|}{ Interim bleeding }} & \\
\hline & & $19 \cdot 9$ & \multirow[t]{2}{*}{0.003} \\
\hline Yes & 74 & $35 \cdot 1$ & \\
\hline \multicolumn{4}{|l|}{ Swabtest } \\
\hline Negative & 480 & $19 \cdot 0$ & \multirow{2}{*}{$<0.001$} \\
\hline Positive & 122 & $33 \cdot 6$ & \\
\hline \multicolumn{4}{|l|}{ Cervical ectopy } \\
\hline Absent & 327 & $15 \cdot 3$ & \multirow[t]{2}{*}{$<0.001$} \\
\hline Gonorrhoea culture & 300 & $29 \cdot 3$ & \\
\hline $\begin{array}{l}\text { Gonorrhoea culture } \\
\text { Negative }\end{array}$ & 601 & $20 \cdot 3$ & \multirow[t]{2}{*}{0.001} \\
\hline Positive & 37 & $46 \cdot 0$ & \\
\hline
\end{tabular}

\begin{tabular}{|c|c|c|}
\hline \multicolumn{3}{|l|}{ Etcosote } \\
\hline & $\begin{array}{l}\text { Corrected } \\
\text { OR }\end{array}$ & $95 \% C L$ \\
\hline \multicolumn{3}{|l|}{ Heterosexual men: ${ }^{\star}$} \\
\hline$<26$ & 1.59 & $1 \cdot 00-2 \cdot 51$ \\
\hline $36-45$ & $0 \cdot 60$ & $0 \cdot 33-1 \cdot 11$ \\
\hline$>45$ & $0 \cdot 31$ & $0 \cdot 10-0.93$ \\
\hline \multicolumn{3}{|l|}{ Contact/warned (ref: no) } \\
\hline $\begin{array}{l}\text { Yes } \\
\text { Ace frst }\end{array}$ & $2 \cdot 53$ & $1 \cdot 50-4 \cdot 26$ \\
\hline \multicolumn{3}{|l|}{$\begin{array}{l}\text { Age first sexual contact (years) } \\
\text { (ref: }>18 \text { ) }\end{array}$} \\
\hline$<13$ & $2 \cdot 50$ & $1 \cdot 01-6 \cdot 21$ \\
\hline $13-18$ & $1 \cdot 58$ & $0 \cdot 88-2 \cdot 83$ \\
\hline Unknown & 1.57 & $0 \cdot 38-6 \cdot 58$ \\
\hline \multicolumn{3}{|l|}{$\begin{array}{l}\text { Last sexual contact with prostitute } \\
\text { (ref: no) }\end{array}$} \\
\hline Yes & 0.48 & $0.25-0.93$ \\
\hline \multicolumn{3}{|l|}{$\begin{array}{l}\text { Appearance urethral discharge } \\
\text { (ref: none) }\end{array}$} \\
\hline Mucous & $2 \cdot 18$ & $1 \cdot 31-3 \cdot 64$ \\
\hline Mucopurulent & $5 \cdot 21$ & $2 \cdot 93-9 \cdot 26$ \\
\hline Purulent & $2 \cdot 02$ & $1 \cdot 07-3 \cdot 80$ \\
\hline \multicolumn{3}{|c|}{$\begin{array}{l}\text { Number of leukocytes in smear or urine } \\
(\text { ref: } 0)\end{array}$} \\
\hline $1-9$ & $2 \cdot 33$ & $0 \cdot 20-26 \cdot 32$ \\
\hline$\geqslant 10$ & $29 \cdot 41$ & $3 \cdot 98-200 \cdot 0$ \\
\hline \multicolumn{3}{|l|}{ Women:t } \\
\hline \multicolumn{3}{|l|}{$\begin{array}{l}\text { Women:T } \\
\text { Age (years) (ref: } 26-35)\end{array}$} \\
\hline$<26$ & $1 \cdot 73$ & $1 \cdot 05-2 \cdot 85$ \\
\hline $36-45$ & $0 \cdot 76$ & $0 \cdot 34-1 \cdot 68$ \\
\hline$>45$ & $0 \cdot 31$ & $0.04-2.68$ \\
\hline \multicolumn{3}{|l|}{ History of STD (ref: no) } \\
\hline Yes & $0 \cdot 56$ & $0.35-0.90$ \\
\hline \multicolumn{3}{|l|}{ Contact/warned (ref: no) } \\
\hline \multicolumn{3}{|l|}{ Cervical friability (ref: no) } \\
\hline Yes & $2 \cdot 00$ & $1 \cdot 19-3 \cdot 34$ \\
\hline Not applicable/unknown & $1 \cdot 12$ & $0 \cdot 27-4 \cdot 64$ \\
\hline \multicolumn{3}{|l|}{$\begin{array}{l}\text { Appearance cervical discharge } \\
\text { (ref: none/mucous) }\end{array}$} \\
\hline (muco)purulent & $1 \cdot 71$ & $1 \cdot 07-2 \cdot 73$ \\
\hline Unknown & $1 \cdot 85$ & $0 \cdot 45-7 \cdot 66$ \\
\hline \multicolumn{3}{|l|}{ Clue cells (ref: negative) } \\
\hline \multirow{2}{*}{\multicolumn{3}{|c|}{ Number of leukocytes in smear (ref: 0 ) }} \\
\hline & & \\
\hline $\begin{array}{l}1-9 \\
\geqslant 10\end{array}$ & $\begin{array}{l}1.44 \\
4.09\end{array}$ & $\begin{array}{l}0 \cdot 83-2 \cdot 51 \\
2 \cdot 31-7 \cdot 22\end{array}$ \\
\hline
\end{tabular}

*Final model, 919 men: $-2 \log \mathrm{L}=631.937, \mathrm{p}=0.0001$. corrected for observed confounding effects of native country. †Final model, 619 women: $-2 \log \mathrm{L}=516.644, \mathrm{p}=0.0001$. Besides for variables shown in the table, the OR was also corrected for observed confounding effects of interim bleeding cervical ectopy and length of use of oral contraceptives. Besides for the variables shown in the table, the OR was also 
Table 4 Sensitivity (Sens), positive predictive value (PPV) and absolute (N) and relative (\%) number of Chlamydia trachomatis-screened men in different screening strategies

Criteria: Sens $90 \%$, PPV 23.7\%

Theoretical approach

Screening in case random$$
\begin{aligned}
& 6 \\
& 5 \\
& 4 \\
& 3 \\
& 2
\end{aligned}
$$

PPV (\%)
0
57
41
29
20
17

$\mathrm{N}$
1
23
133
425
727
902

of all 6 independent predictors of chlamydia trachomatis (see table 3) are present

Medical approach
Screening in case of
1 anamnestic predictor
2 anamnestic predictors
1 anamnestic +
(muco)purulent discharge
1 anamnestic +
ten or more leucocytes

$\begin{array}{llll}\text { Sens }(\%) & \text { PPV (\%) } & \text { N } & \% \\ 95 & 18 & 795 & 84 \cdot 4 \\ 47 & 25 & 277 & 29 \cdot 4 \\ 71 & 29 & 363 & 38 \cdot 5 \\ 93 & 25 & 554 & 58 \cdot 8\end{array}$

*anamnestic predictors: age below 26 years, being traced as an STD contact, age first sexual contact below 13 and last sexual contact with a non-prostitute.

Table 5 Sensitivity (Sens), positive predictive value (PPV) and absolute (N) and relative (\%) number of Chlamydia trachomatis-screened women in different screening strategies

\begin{tabular}{|c|c|c|c|c|}
\hline \multicolumn{5}{|l|}{ Criteria: Sens $95 \%$, PPV $32.3 \%$} \\
\hline $\begin{array}{l}\text { Theoretical approach } \\
\text { Screening in case random } \\
\quad 7 \\
6 \\
5 \\
4 \\
3 \\
2 \\
1 \\
\text { of all } 7 \text { independent predictors of cl }\end{array}$ & $\begin{array}{l}\text { Sens }(\%) \\
<1 \\
9 \\
32 \\
52 \\
79 \\
91 \\
99 \\
\text { hlamydia tra }\end{array}$ & $\begin{array}{l}\text { PPV (\%) } \\
100 \\
92 \\
64 \\
46 \\
35 \\
27 \\
23 \\
\text { matis (see t }\end{array}$ & $\begin{array}{r}\mathrm{N} \\
1 \\
13 \\
69 \\
158 \\
312 \\
468 \\
599 \\
3) \text { are }\end{array}$ & $\begin{array}{l}\% \\
0 \cdot 2 \\
2 \cdot 0 \\
10 \cdot 8 \\
24 \cdot 6 \\
48 \cdot 7 \\
73 \cdot 0 \\
93 \cdot 4\end{array}$ \\
\hline $\begin{array}{l}\text { Medical approach } \\
\text { Screening in case of } \\
1 \text { anamnestic predictor } \\
1 \text { anamnestic }+1 \text { physical } \dagger \\
1 \text { anamnestic }+ \text { laboratory } \neq \\
1 \text { anamnestic }+1 \text { physical }+1 \text { lab. }\end{array}$ & $\begin{array}{l}\text { Sens }(\%) \\
86 \\
96 \\
96 \\
94\end{array}$ & $\begin{array}{c}\text { PPV (\%) } \\
26 \\
24 \\
24 \\
25\end{array}$ & $\begin{array}{l}\mathrm{N} \\
\mathbf{4 5 5} \\
553 \\
551 \\
534\end{array}$ & $\begin{array}{l}\% \\
71 \cdot 0 \\
86 \cdot 3 \\
86 \cdot 0 \\
83 \cdot 3\end{array}$ \\
\hline
\end{tabular}

*anamnestic predictors: age below 26 years, no history of STD and being traced as an STD contact.

tphysical predictors: (muco)purulent cervical discharge, cervical friability.

flaboratory predictors: clue cells positive, ten or more leukocytes in urethral smear.

with a non-prostitute, (muco)purulent urethral discharge and at least ten leukocytes per field in a Gram-stained urethral smear or in first catch urine (table 3). For women independent predictors were: age below 26 years, no history of STD, being an STD contact, cervical friability, (muco)purulent cervical discharge, presence of clue cells and ten or more leukocytes per field in a Gram-stained urethral smear (table 3).

Screening strategies

Different sets of the above mentioned independent predictors of $C$ trachomatis infection (six for men, seven for women) were used as selection criterion for screening. The aimed PPV of 1.5 times the observed $C$ trachomatis infection prevalence corresponded with $23.7 \%$ for men and $32.3 \%$ for women. Figure 1 shows the sensitivity, the PPV and the number of heterosexual men tested for $C$ trachomatis in different strategies. In the theoretical approach an increasing proportion of the target population was offered screening, with a declining number of predictors. As a consequence, the PPV declined from $57 \%$ to $17 \%$ with increasing sensitivity. If screening would be restricted to men meeting random $6,5,4$ or 3 of all 6 predictors, only $0 \%, 9 \%, 37 \%$ and $83 \%$ of the

infected cases would be identified, respectively. Offering $C$ trachomatis screening to men with two predictors (77\%) would identify $98 \%$ of the infected men, but the PPV would be too low (20\%). Also, specific combinations of two predictors did not yield a sensitivity of $90 \%$ and a PPV of $24 \%$ at the same time. The best single criterion was the presence of ten or more leukocytes in urethral smear or urine (69\% of all men); sensitivity $98 \%$, PPV $23 \%$. The medical approach showed that the presence of at least one anamnestic predictor would not satisfy the screening criteria (table 4): sensitivity $95 \%$, PPV $18 \%$, percentage to be tested 84 . If the presence of (muco)purulent discharge was included in the screening strategy, in addition to one (random) anamnestic predictor, the sensitivity was too low $(71 \%)$. However, if the presence of ten or more leukocytes was included, again in addition to one anamnestic predictor, the criteria were satisfied with $59 \%$ of the population tested and a sensitivity of $93 \%$ and PPV of $25 \%$. Further expansion of the criteria with information on discharge did not result in an increase of sensitivity or PPV.

For women, the only satisfying strategy in the theoretical approach, with respect to the sensitivity, would be to test women with one predictor (sensitivity 99\%). However, the criterion for PPV would not be met $(23 \%)$ and still $93 \%$ of all women had to be tested. (table 5) No strategies based on single predictors could be found to improve the sensitivity and the PPV at the same time. Also, the medical approach did not offer satisfying results. With the information from the medical history only, the sensitivity was too low (86\%). If the presence of cervical friability or (muco)purulent discharge was included as criterion, the sensitivity rose to $96 \%$, but the PPV remained too low. Using the information on the presence of clue cells and the number of leukocytes showed similar results.

Based on the interim analyses of the data from 1986 and 1987, it was decided to screen all women as well as all men with urethritis on the presence of $C$ trachomatis, from 1989 onwards. Since October 1991 all men were tested.

\section{Evaluation of chosen screening strategy}

The prevalence of $C$ trachomatis infection in men decreased from $15.8 \%$ in $1986-1988$ to $7 \cdot 5 \%$ in 1993 and for women from $21.5 \%$ to $7 \cdot 3 \%$. Also, the prevalence of gonorrhoea had declined in 1993 , to $5.4 \%$ for men and $1.9 \%$ for women. The observed decrease in $C$ trachomatis infection may be due to changes in the composition of the population, rather than to a real drop in the prevalence. In order to determine whether this was the case, the characteristics of visitors and the prevalence in several subgroups of 1986-1988 were compared with those of 1993. Heterosexual men in 1993 had a Turkish nationality more often, were prostitute's clients more often and were an STD contact less often as compared with the study population in 1986-1988 (table 6). Thus, in 1993 an increase was observed in the 
Table 6 Characteristics of visitors attending an STD clinic in Amsterdam in 1986-1988 (sample) and in 1993 (total group) and Chlamydia trachomatis prevalences in the different subgroups.

\begin{tabular}{|c|c|c|c|c|}
\hline & $1986-88$ & 1993 & $\begin{array}{l}1986-1988 \\
\text { (\% chlamydia trachomatis } 15 \cdot 8) \\
\text { Chlamydia trachomatis prevalence } \\
\text { in the subgroup }\end{array}$ & $\begin{array}{l}1993 \\
\text { (\% chlamydia trachomatis } 7 \cdot 5) \\
\text { Chlamydia trachomatis prevalence } \\
\text { in the subgroup }\end{array}$ \\
\hline $\begin{array}{l}\text { Heterosexual men } \\
\text { Nationality }{ }^{\star}\end{array}$ & $\mathrm{n}=947$ & $\mathrm{n}=5615$ & & \\
\hline Dutch & $72 \cdot 9$ & $52 \cdot 5$ & $18 \cdot 1$ & $7 \cdot 5$ \\
\hline Moroccan & $4 \cdot 1$ & $6 \cdot 2$ & $12 \cdot 8$ & $6 \cdot 1$ \\
\hline Turkish & $5 \cdot 1$ & $20 \cdot 8$ & $8 \cdot 3$ & $8 \cdot 1$ \\
\hline Other & $18 \cdot 0$ & $20 \cdot 5$ & $10 \cdot 1$ & $7 \cdot 3$ \\
\hline \multicolumn{5}{|l|}{ Age $\ddagger$} \\
\hline$<26$ years & $21 \cdot 8$ & $23 \cdot 3$ & $24 \cdot 4$ & $10 \cdot 9$ \\
\hline $26-35$ years & $51 \cdot 1$ & $46 \cdot 8$ & $16 \cdot 5$ & $7 \cdot 5$ \\
\hline $36-45$ years & $18 \cdot 3$ & 20.5 & 9.9 & $5 \cdot 3$ \\
\hline$>45$ years & $8 \cdot 8$ & $9 \cdot 4$ & $4 \cdot 8$ & $3 \cdot 8$ \\
\hline \multicolumn{5}{|l|}{ Prostitute client ${ }^{\star}$} \\
\hline Yes & $28 \cdot 0$ & $34 \cdot 3$ & $\begin{array}{r}5 \cdot 7 \\
19 \cdot 9\end{array}$ & $6 \cdot 8$ \\
\hline \multicolumn{5}{|l|}{ Being an STD contact ${ }^{\star}$} \\
\hline Yes & $13 \cdot 8$ & $6 \cdot 1$ & $25 \cdot 4$ & $9 \cdot 1$ \\
\hline No & $86 \cdot 2$ & 93.9 & $14 \cdot 4$ & $7 \cdot 4$ \\
\hline \multicolumn{5}{|l|}{ Former gonorrhoea/syphilis } \\
\hline Yes & $42 \cdot 0$ & $30 \cdot 0$ & $16 \cdot 9$ & $8 \cdot 0$ \\
\hline No & $58 \cdot 0$ & $70 \cdot 0$ & $15 \cdot 2$ & $7 \cdot 3$ \\
\hline \multirow[t]{2}{*}{ Current diagnosis of gonorrhoea } & $10 \cdot 7$ & $5 \cdot 4$ & $17 \cdot 8$ & $12 \cdot 3$ \\
\hline & $1986-88$ & 1993 & $\begin{array}{l}1986-1988 \\
(\% \text { chlamydia trachomatis } 21 \cdot 5) \\
\text { Chlamydia trachomatis prevalence } \\
\text { in the subgroup }\end{array}$ & $\begin{array}{l}1993 \\
(\% \text { chlamydia trachomatis } 7 \cdot 3 \text { ) } \\
\text { Chlamydia trachomatis prevalence } \\
\text { in the subgroup }\end{array}$ \\
\hline Women & $n=648$ & $\mathrm{n}=4548$ & & \\
\hline \multicolumn{5}{|l|}{ Nationality } \\
\hline Dutch & $86 \cdot 3$ & $71 \cdot 7$ & $21 \cdot 3$ & $7 \cdot 1$ \\
\hline Moroccan & $13 \cdot 7$ & $28 \cdot 3$ & $23 \cdot 9$ & $7 \cdot 7$ \\
\hline \multicolumn{5}{|l|}{ Age $\ddagger$} \\
\hline$<26$ years & $37 \cdot 2$ & $37 \cdot 1$ & $31 \cdot 1$ & $12 \cdot 0$ \\
\hline $26-35$ years & $43 . \overline{9}$ & $41 \cdot 2$ & 18.9 & $5 \cdot 2$ \\
\hline $36-45$ years & $15 \cdot 6$ & $16 \cdot \overline{6}$ & $11 \cdot 0$ & $3 \cdot \overline{2}$ \\
\hline$>45$ years & $3 \cdot 3$ & $5 \cdot 2$ & $4 \cdot 8$ & $2 \cdot 6$ \\
\hline \multicolumn{5}{|l|}{ Prostitutet } \\
\hline Yes & $14 \cdot 8$ & $29 \cdot 5$ & $22 \cdot 1$ & $4 \cdot 6$ \\
\hline No & $85 \cdot 2$ & $70 \cdot 5$ & $21 \cdot 6$ & $8 \cdot 4$ \\
\hline \multicolumn{5}{|l|}{ Being an STD contact } \\
\hline Yes & $34 \cdot 5$ & $12 \cdot 5$ & $32 \cdot 1$ & $16 \cdot 8$ \\
\hline No & $65 \cdot 5$ & $87 \cdot 5$ & $16 \cdot 2$ & $5 \cdot 9$ \\
\hline \multicolumn{5}{|l|}{ Former gonorrhoea/syphilis $\ddagger$} \\
\hline Yes & $25 \cdot 3$ & $21 \cdot 5$ & $14 \cdot 8$ & $3 \cdot 5$ \\
\hline No & $74 \cdot 7$ & $78 \cdot 5$ & $24 \cdot 0$ & $8 \cdot 3$ \\
\hline Current diagnosis of gonorrhoea & $5 \cdot 7$ & 1.9 & $46 \cdot 0$ & $29 \cdot 4$ \\
\hline
\end{tabular}

*Only significantly associated with Chlamydia trachomatis in 1986-1988.

†Only significantly associated with Chlamydia trachomatis in 1993.

¥Significantly associated with Chlamydia trachomatis in 1986-1988 and 1993

proportion of individuals at low risk for $C$ trachomatis infection in 1986-1988 (see tables 2 and 3). However, this could not explain the decreasing $C$ trachomatis infection prevalence in men, because the decline in $C$ trachomatis was also found for high-risk subgroups like young age groups, STD contacts, men with Dutch nationality and those denying having sex with prostitutes (table 4). The prevalence remained constant in Turkish men and prostitute's clients. In $1993 C$ trachomatis infections in men were still associated with young age, but they were no longer associated with Dutch nationality, being an STD contact or denial of having sex with prostitutes: this revealed a change in the risk profile of $C$ trachomatisinfected men in 1993.

Major differences in women attending the clinic in 1993 compared with the earlier study population of 1986-1988 were found for nationality (foreign nationality more often), being a prostitute (more often) and being an STD contact (less often) (table 4). Except for being an STD contact, these characteristics were not associated with $C$ trachomatis in the study of 1986-1988. The declining number of STD contacts (directly related to the decreasing number of index cases) was not expected to account for the drop in $C$ trachomatis infec- tion prevalence. The decline in 1993 proved to be for all female subgroups (table 4). As a consequence, $C$ trachomatis-infected women in 1993 were of young age, an STD contact and co-infected with $N$ gonorrhoeae more often and had no history of STD more often, corresponding with the risk profile in 1986-1988.

\section{Discussion}

$C$ trachomatis infections proved to be far more prevalent than gonorrhoea among heterosexual visitors of the STD clinic in 1986-1988. The $C$ trachomatis prevalences of $15 \cdot 8 \%$ for heterosexual men and $21.5 \%$ for women are comparable with results from other studies in similar populations. ${ }^{13-20}$ The $C$ trachomatis infection prevalence for men may be a little overestimated because relatively few Turkish men participated and lower $C$ trachomatis prevalences were found in this group. On the other hand, the lower age of the male non-participants may have caused an underestimation in the study. The independent predictors for $C$ trachomatis infection, especially young age, mucopurulent discharge, cervical friability, ten or more leukocytes in urethral smear or urine and being an STD contact, correspond with those found by others. ${ }^{37813141721}$ We found 
that female visitors who reported a former STD were less likely to be presently infected with chlamydia compared with women without such history, after adjustment for other risk factors. Because $C$ trachomatis infection and salpingitis represented more than half of the self-reported STD, the relationship might be explained by partial immunity for $C$ trachomatis induced by a primary infection. For men we failed to demonstrate an identical association, which we cannot explain.

It is concluded that for heterosexual men selective screening for $C$ trachomatis infections was satisfying. The best option would be to test those with one anamnestic predictor for $C$ trachomatis infection in addition to ten or more leukocytes in smear or urine. This strategy would test only $59 \%$ of the heterosexual men, while detecting $93 \%$ of the $C$ trachomatis cases. The actual choice in this clinic, screening men with urethritis, proved to be almost just as good: testing $69 \%$ of the men identified $98 \%$ of cases with a PPV of $23 \%$. However, for women only universal screening proved to be suitable. This recommendation corresponds with the decision made for women in this STD clinic in 1989 and also corresponds with the updated set of guidelines for prevention and control of $C$ trachomatis in the United States. ${ }^{22}$

The contribution of a predictor to the proportion of cases detected in screening programmes depends on the magnitude of the association and the prevalence of the predictor in the population. Variables linked to less than $15 \%$ of cases or more than $85 \%$ of all individuals are of limited value as selection criteria, because they cannot discriminate properly between cases and healthy individuals. ${ }^{14}$ Efforts to design screening programmes in different health care settings regularly succeeded ${ }^{6-810}$ but were less successful as well. ${ }^{142023-26}$ Available studies in STD clinics argue unanimously in favour of universal screening. ${ }^{142026}$

It must be noted that our study of 1986-1988 may have some shortcomings. The cell culture was used for the diagnosis of $C$ trachomatis infection. However, recent developments in laboratory techniques demonstrate that the sensitivity of the culture is not $100 \% .{ }^{27-29}$ Consequently, some individuals may have been wrongly classified as $C$ trachomatis negative, resulting in an underestimation of the ORs. However, it is unlikely that a predictor strongly associated with $C$ trachomatis infection was missed.

Because a decline in the prevalence of STD is to be expected some time after introducing screening, an evaluation is necessary and allows for adjustments. ${ }^{9}$ The $C$ trachomatis infection prevalence in the STD clinic between 1986-1988 and 1993 decreased about $50 \%$ for men and $66 \%$ for women. Because of depletion of the reservoir of asymptomatically infected, which are mainly females, the screening programme was probably more effective for women. In 1993 the $C$ trachomatis prevalence was similar for men $(7 \cdot 5 \%)$ and women $(7 \cdot 3 \%)$.
The observed decrease may partly be artificial because for 1993 the entire STD population was used, including users of antibiotics in the past month, individuals with a prior visit in the past month and foreign travellers leaving the Netherlands within six weeks. These were excluded in 1986-1988. The declining prevalence in 1993 could not be explained by the increasing proportion of low-risk individuals, because the decrease was also observed in the high-risk groups. This suggests the success of the screening programme. The drop in the prevalence of $C$ trachomatis infection may also be due to the reduction of high-risk behaviour, as supported by equally declining prevalences of gonorrhoea. The absence of a decline in $C$ trachomatis among Turkish men and those visiting prostitutes may implicate that preventive campaigns for safer sex have not (effectively) reached these groups. Evidence for this was found by Haastrecht et al, who reported that the adoption of safer sexual practices in heterosexuals did not apply to the Turkish men. ${ }^{30}$ Furthermore, it is supported by high levels of gonorrhoea, especially of penicillinase producing $N$ gonorrhoeae found in other studies among these groups in Amsterdam. ${ }^{31}$ Specifically designed prevention efforts should be made to achieve a reduction in the prevalence of STD in this group.

It is very likely that screening in addition to reduction of high-risk behaviour contributed to the decrease in the prevalence of $C$ trachomatis infection among visitors attending the STD clinic. Unfortunately, these effects could not be unravelled because no data were available on sexual behaviours in 1993, such as the number of partners or the use of condoms. Independent predictors of $C$ trachomatis infection are helpful in defining the criteria for screening programmes. At our STD clinic universal screening has been performed since 1989 for women and since October 1991 for men, although for men theoretically selective screening could be satisfactory. Nonetheless, universal screening was preferred by the physicians working in the clinic and selective screening was ended since the introduction of the cheaper ELISA for diagnosis in men. The risk profile of $C$ trachomatis-infected women had not changed between 1986-1988 and 1993, but it had changed for men. Monitoring of predictors for $C$ trachomatis infection is advocated. If the decrease in $C$ trachomatis prevalence continues in the next few years, the criteria for screening need to be adjusted because the risk profiles for $C$ trachomatis infections may have altered and universal screening may no longer be cost-effective over a predictor-based programme for selective screening.

The authors thank Joan Kint for her efforts in the genera The authors thank Joan Kint for her efforts in the general nary work on the data sets and Charles Henquet, head of the nary work on the data sets and Charles Henquet, head of the
STD clinic and all personnel of the clinic for their cooperation in the study.

1 Nugent RP, Hillier SL for the investigators of the Johns Hopkins study of cervicitis and adverse pregnancy out- 
come. Mucopurulent cervicitis as a predictor of chlamydial infection and adverse pregnancy outcome. Sex Transm Dis 1992;19:198-202.

2 Rahm V-A, Gnarpe H, Odlind V. Chlamydia trachomatis among sexually active teenage girls. Lack of correlation between chlamydial infection, history of the patient and clinical signs of infection. Br $\mathcal{F}$ Obstet Gynaecol 1988; 95:916-9.

3 Malotte KC, Wiesmeier E, Gelineau KJ. Screening for chlamydial cervicitis in a sexually active university population. Am $\mathcal{f}$ Public Health 1990;80:469-71.

4 Thejls H, Rahm V-A, Rosen G, Gnarpe H. Correlation between chlamydia infection and clinical evaluation, vaginal wet smear, and cervical swab test in female adolescents. Am $\mathcal{f}$ Obstet Gynecol 1987;157:974-6.

5 Parsons WL, Godwin M, Robbins C, Butler R. Prevalence of cervical pathogens in women with and without inflammatory changes on smear testing. $B M 7$ 1993;306: 1173-5.

6 Handsfield HH, Jasman LL, Roberts PL, Hanson VW, Kothenbeutel RL, Stamm WE. Criteria for selective screening for Chlamydia trachomatis infection in women attending family planning clinics. $\mathcal{F} A M A$ 1986;255: $1730-4$.

7 Addiss DG, Vaughn ML, Holzhueter MA, Bakken LL, Davis JP. Selective screening for Chlamydia trachomatis infection in nonurban family planning clinics in Wisconsin. Fam Plann Perspect 1987;19:252-6.

8 Addiss DG, Vaughn ML, Golubjatnikov R, Pfister Kurtycz DFI, Davis JP. Chlamydia trachomatis infection Kurtycz DFI, Davis JP. Chlamydia trachomatis infection in women attending urban midwestern family planning
and community health clinics: risk factors, selective and community health clinics: risk factors, selective screening and evaluation of
Transm Dis 1990;17:138-46.

9 Addiss DG, Vaughn ML, Ludka D, Pfister J, Davis JP. Decreased prevalence of Chlamydia trachomatis infection associated with a selective screening program in family planning clinics in Wisconsin. Sex Transm Dis 1993; 20:28-35.

10 Stergachis A, Scholes D, Heidrich FE, Sherer DM, Kolmes $\mathrm{KK}$, Stamm WE. Selective screening for Chlamydia trachomatis infection in a primary care population of chomatis infection in a primary care

11 van den Hoek JAR, van Haastrecht HJA, Fennema JSA Kint JAPCM, van Doornum, GJ, Coutinho RA. Vóórkomen en risicofactoren van infectie met Chlamydia trachomatis bij bezoekers van een geslachtsziekten polikliniek in Amsterdam (in Dutch) Ned Tijdschr Geneeskd 1989;133:2392-6.

12 Ossewaarde JM, Rieffe M, van Doornum GJ, Henquet CJM, van Loon AM. Detection of amplified chlamydial DNA using a microtiter plate-based enzyme immunoassay. Eur $f$ Clin Microbiol Infect Dis 1994;13: $732-41$.

13 Thewessen EAPM, van der Meijden WI, Doppenberg HJAT, Mulder PGH, Wagenvoort JHT, Stolz E, Michel MF. Screening for cervical Chlamydia trachomatis infections in two Dutch populations. Genitourin Med 1990; tions in two

14 Hart G. Factors associated with genital chlamydial and gonococcal infection in females. Genitourin Med 1992; 68:217-20

15 Hook EW III, Reichart CA, Upchurch DM, Ray P, Celentano D, Quinn TC. Comparative behavioural epidemiology of gonococcal and chlamydial infections among patients attending a Baltimore, Maryland, sexually transmitted disease clinic. Am $\mathcal{f}$ Epidemiol 1992; 136:662-72.
16 Barnes RC, Katz BP, Rolfs RT, Batteigner B, Caine V, Jones RB. Quantitative culture of endocervical Chlamydia Jones RB. Quantitative culture of endocervical

17 Pereira LH, Embil JA, Haase DA, Manley KM. Cytomegalovirus infection among women attending a sexually transmitted disease clinic: association with clinical symptoms and other sexually transmitted diseases. $A m \mathcal{F}$ Epidemiol 1990;131:683-92.

18 Lin J-S, Jones WE, Yan L, Withwein KA, Flaherty EE, Haivanis RM, Rice PA. Underdiagnosis of Chlamydia trachomatis infection. Diagnostic limitations in patients with low-level infection. Sex Transm Dis 1992;19: 259-65.

19 Rietmeijer CAM, Judson FN, Boele van Hensbroek M, Ehret JM, Douglas JM. Unsuspected Chlamydia trachomatis in heterosexual men attending a sexually transchomatis in heterosexual men attending a sexually transmitted disease clinic: evaluation of risk factors
screening methods. Sex Transm Dis 1991;19:28-35.

20 Hart G. Factors associated with genital chlamydial and gonococcal infection in males. Genitourin Med 1993;69: 393-6.

21 Magder LS, Harrison HR, Ehret JM, Anderson TS, Judson FN. Factors related to genital Chlamydia trachomatis and its diagnosis by culture in a sexually transmitted disease clinic. Am f Epidemiol 1988;28:298-308.

22 CDC. Recommendations for the prevention and management of Chlamydia trachomatis infections, 1993. MMWR; 42 (RR-11): 1-36.

23 Weinstock HS, Bolan GA, Kohn R, Balladares C, Back A, Oliva G. Chlamydia trachomatis infection in women: a need for universal screening in high prevalence populaneed for universal screening in high pre
tions? Am $\mathcal{F}$ Epidemiol 1992;135:41-7.

24 Schachter J, Stonet E, Moncada J. Screening for chlamydial infections in women attending family planning clinics. Evaluation of presumptive indicators for therapy. West f Med 1983;138:375-9.

25 Winter L, Goldy S, Baer C. Prevalence and epidemiologic correlates of Chlamydia trachomatis in rural and urban populations. Sex Transm Dis 1990;17:30-6.

26 Kent GP, Harrison R, Berman SM, Keenlyside RA. Screening for Chlamydia trachomatis infection in a sexually transmitted disease clinic: comparison of diagnostic tests with clinical and historical risk factors. Sex Transm Dis $1988 ; 15: 51-7$.

27 de Barbeyrac B, Pellet I, Dutilh B, Bébéar C, Dumon B, Géniaux M, Bébéar Ch. Evaluation of the Amplicor Chlamydia trachomatis test versus culture in genital samples in various prevalence populations. Genitourin Med 1994;70:162-6.

28 Kessler HH, Pierer K, Stuenzer D, Auger-Grumbach P, Haller E-M, Marth E. Rapid detection of Chlamydia trachomatis in conjunctival, pharyngeal and urethral specimens with a new polymerase chain reaction assay. Sex Transm Dis 1994;21:191-5.

29 Bianchi A, Scieux C, Brunat N, Vexiau D, Kermanach M, Pezin P, Janier M, Morel P, Lagrange PH. An evaluation of the polymerase chain reaction Amplicor Chlamydia traof the polymerase chain reaction Amplicor Chlamydia trachomatis in male urine and female

30 van Heatrinho RA. Evidence for a change in behaviour among heterosexuals in Amsterdam under the influence of AIDS. Genitourin Med 1991;67:199-206.

31 Prins M, Bindels PJE, Coutinho RA, Henquet CJM, Doornum GJ van, Hoek JAR van den. Determinants of penicillinase producing Neisseria gonorrhoeae infections in heterosexuals in Amsterdam. Genitourin Med 1994;70: 247-52. 